\title{
HISTÓRIA DA EDUCAÇÃO E JORNAIS: EM BUSCA DE UMA INFÂNCIA PLURAL
}

\author{
HISTORY OF EDUCATION AND NEWSPAPERS: IN SEARCH OF A PLURAL CHILDHOOD \\ HISTORIA DE LA EDUCACIÓN Y PERIÓDICOS: EN BUSQUEDA DE UNA INFANCIA PLURAL
}

\author{
AREND, Silvia Maria Fávero ${ }^{1}$ \\ LAZAROTTO, Aline Fátima²
}

\section{RESUMO}

Este artigo tem por objetivo analisar os estudos sobre História da Educação, produzidos nos programas de pós-graduação em Educação do Brasil, entre 2013 e 2018, que utilizaram os jornais publicados no país como fonte documental. A análise caminha em dois sentidos, conectados. Inicialmente, traçamos um panorama sobre o uso de jornais pelos pesquisadores; posteriormente, identificamos as infâncias descritas nas narrativas a partir do mencionado documento. Com esta análise pretendemos demonstrar que os jornais brasileiros, que estão disponíveis para a pesquisa em arquivos, bibliotecas e sites, podem contribuir para a ampliação do conhecimento da História da Educação.

Palavras-chave: História da Educação. Jornal. Infância. Brasil.

\section{ABSTRACT}

The objective of this paper is to analyze the studies of Education History, carried out in the Education post-graduation programs in Brazil between 2013 and 2018, Using newspapers published in Brazil as a documentary source. This study is developed in two interconnected directions. Firstly, we created an overview of newspapers made by researchers; then we identified children in narratives starting from the document mentioned above. Throughout this analysis we aim to demonstrate that Brazilian newspapers that are available files research, libraries and websites, can contribute greatly to the expansion of the History of Education knowledge.

Keywords: History of Education. Newspaper. Childhood. Brazil.

\section{RESUMEN}

Este artículo tiene como objetivo analizar los estudios sobre Historia de la Educación producidos en los programas de posgrado en Educación en Brasil, entre el 2013 y el 2018, que utilizaron los periódicos publicados en el país como fuente documental. Este análisis camina en dos sentidos. Comenzamos trazando un panorama sobre el uso de los periódicos por los investigadores; luego, identificamos las infancias descritas en las narrativas a partir del mencionado documento. Con este análisis pretendemos demostrar que los periódicos brasileños, disponibles para la investigación en archivos, bibliotecas y sitios web, pueden contribuir para la ampliación del conocimiento de la Historia de la Educación.

Palabras clave: Historia de la Educación. Periódico. La infancia. Brasil.

\footnotetext{
${ }^{1}$ Universidade do Estado de Santa Catarina - UDESC - Brasil.

${ }^{2}$ Universidade do Estado de Santa Catarina - UDESC - Brasil. Bolsista UNIEDU/FUMDES.
} 


\title{
INTRODUÇÃO
}

As investigações em torno da História da Infância brasileira ainda centram, em grande medida, seu foco nos debates relativos a essa população enquanto problema social (MOURA; AREND, 2016). Por um lado, como afirma Souza (2018), alguns temas foram incorporados pela História da Educação no Brasil de forma tangencial. Por exemplo, apenas 3,5\% dos estudos publicados na Revista Brasileira de História da Educação entre 2001 e 2010 tinham como temática a infância ou a educação infantil. Entendemos que essa falta de "diálogo" entre a História da Infância e a História da Educação, justamente por se tratar de campos conectados, merece atenção, uma vez que os discentes brasileiros, público alvo da educação escolar no século $X X$, são majoritariamente crianças, adolescentes e jovens de ambos os sexos. A educadora estadunidense Barbara Finkelstein, em importante estudo publicado na década de 1980, inferia sobre esse problema:

\begin{abstract}
Se entende adecuadamente que la historia de la educación, un campo de estúdio dinâmico y complejo, abarca múltiples pareceres hasta ahora sin sintetizar sobre la evolución y el carácter de ideas medidas y práticas educativas. Por tanto, no resulta sorprendente descobrir que los historiadores de la educación parezcan haberse interessado por niños y jovens de modo diverso y selectivo - ampliando y profundizando en el contenido de lo que han estudiado y como lo han estudiado - sin transformar necesariamante de manera fundamental sus esquemas interpretativos o sus métodos analíticos. Sólo muy pocos historiadores han sido sistemáticos em uma tentativa de conectar la história de la infância a la formación de los niños con la historia de la educación, centrándose en los aprendices y en el aprendizaje como aspectos fundametnales en el estúdio de la historia educativa. (FINKELSTEIN, 1986, p. 21).
\end{abstract}

O presente artigo busca problematizar essa possibilidade de conexão entre as áreas da História da Educação e da História da Infância, elegendo os jornais como fonte privilegiada para a reflexão sobre o processo de ampliação do campo de estudos a respeito dos infantes. De acordo com Kulhmann e Leonardi, é preciso, em relação à História da Educação, superar os limites de se produzir interpretações historiográficas restritas ao educentrismo, "expressão que enfatiza as limitações de se tratar as questões da educação como produzidas exclusivamente na dimensão do escolar" (2017, p. 209).

Já Cristina Ponte (2005), importante pesquisadora portuguesa da área da comunicação social, afirma que os jornais contribuíram sobremaneira para a construção de discursos sobre a infância, especialmente a partir da segunda metade do século XX no Ocidente. Para a autora, até o início da década de 1970, apesar do crescente interesse pelas temáticas da educação escolar e da assistência social, a criança, o adolescente e o jovem não constituíam pauta constante das agendas jornalísticas dos periódicos. Foi com o advento do movimento social da Contracultura e das políticas sociais emanadas da Organização das Nações Unidas (ONU), sobretudo a partir de 1989, com a aprovação da

\footnotetext{
${ }^{3}$ Essa pesquisa foi financiada pelo Projeto "Brasil em notícias: narrativas sobre famílias e infâncias (1964-1990)". Chamada pública da FAPESC $n^{\circ}$ 01/2016 - Apoio à infraestrutura para os grupos de pesquisa da Universidade do Estado de Santa Catarina (UDESC).
} 
Convenção sobre os Direitos das Criança, que esse grupo social passou a ser "notícia" com grande regularidade nos jornais, especialmente nos de circulação nacional e regional.

Apesar da recente centralidade da infância no discurso jornalístico, os pesquisadores brasileiros da área da História da Infância têm produzido estudos a partir dessa fonte documental. Tais estudos têm como foco específico as temáticas da construção de um mercado consumidor infantojuvenil no século XX (BRITES, 2000), da assistência social (DAMINELLI, 2018) e dos fenômenos associados à disciplinarização dos corpos infantis (DIONÍSIO; GIRARDELLO, 2009).

Em relação à educação no Brasil, Faria Filho (2002) afirma que o discurso enunciado nos jornais teve um papel importante, para a área, desde o século XIX. Para o autor, através de matérias jornalísticas publicadas nesses veículos de comunicação, é possível conhecer as estratégias utilizadas pelos diferentes agentes sociais na conformação de um campo pedagógico nacional e/ou regional, bem como na legitimação da escola como instituição central para formação intelectual da população infantojuvenil no país. Bastos (2002) entende a imprensa como um "dispositivo" do campo do social, pela função do discurso jornalístico de informar/enunciar acontecimentos, ideários e saberes, revelando cenários sociais e sujeitos. Magaldi e Xavier (2008), por sua vez, assinalam o quanto a utilização desta fonte tem ganhado em representatividade no campo da História da Educação, devido à ampla variedade de veículos existentes no país desde o século XIX. Concluem as autoras que a imprensa permite que o pesquisador tenha "acesso" a uma sociedade brasileira multifacetada, pautada por problemas sociais e por políticas educacionais de diferentes naturezas teóricas, implementadas ao longo do tempo no país.

Este artigo objetiva analisar os estudos sobre História da Educação, produzidos nos programas de pós-graduação em Educação brasileiros, que utilizaram o jornal como fonte documental. Esta análise caminha em dois sentidos, entre si interligados: em um primeiro momento, traçamos um panorama sobre os usos dos jornais pelos pesquisadores; num segundo momento, identificamos as infâncias (além da experiência de ser aluno/a) descritas nessas narrativas históricas a partir do mencionado documento. Pretendemos, com tal análise, demonstrar o quanto essa fonte documental, que está disponível para a pesquisa no Brasil em arquivos, bibliotecas (públicas ou privadas), em hemerotecas digitais ${ }^{4}$ e em sites/portais ${ }^{5}$, pode contribuir para a ampliação do conhecimento da História da Educação.

\section{USO DOS JORNAIS EM NARRATIVAS DE HISTÓRIA DA EDUCAÇÃO ENTRE 2013 E 2018}

Para o presente estudo, realizamos uma investigação em um importante espaço de socialização de pesquisas acadêmicas no Brasil: o Catálogo de Teses e Dissertações da Coordenação de Aperfeiçoamento de Pessoal de Nível Superior - Capes/Ministério da Educação/Brasil (https://catalogodeteses.capes.gov.br/catalogo-teses/\#!/). Dentre as produções acadêmicas desse

\footnotetext{
${ }^{4}$ Sobre as hemerotecas digitais brasileiras, ver, por exemplo, os repositórios digitais: Biblioteca Nacional digital (https://bndigital.bn.gov.br/hemeroteca-digital/); Hemeroteca Digital Catarinense (http://hemeroteca.ciasc.sc.gov.br/); Arquivo do Estado de São Paulo (http://www.arquivoestado.sp.gov.br/site/acervo/repositorio_digital/jornais_revistas).

${ }^{5}$ Ver, por exemplo, o acervo digital do jornal Folha de São Paulo: <https://acervo.folha.com.br/index.do>.
} 
repositório digital, que abriga parte dos resultados da ciência brasileira, selecionamos as dissertações e teses produzidas entre 2013 e 2018 nos programas de pós-graduação em Educação. A escolha desse período se deu em função da expansão ocorrida na área da pós-graduação brasileira desde o início dos anos 2000, que gerou um aumento da produção acadêmica dos trabalhos de conclusão de curso em nível de mestrado e doutorado, bem como de artigos científicos de divulgação.

A metodologia utilizada no processo de coleta e análise dos dados foi a denominada Análise de Conteúdo temática, conforme preconiza Laurence Bardin (1977). Inicialmente, como afirma a autora, selecionamos os documentos e os cotejamos a partir das regras de exaustividade, representatividade, homogeneidade e pertinência. Em seguida realizamos o processo de categorização do material coletado utilizando determinados descritores que apresentamos no parágrafo abaixo. Posteriormente, tendo em vista o material selecionado, efetuamos o processo de análise a partir de indagações relativas ao uso dos jornais na construção da narrativa, utilização de referenciais teórico-metodológicos e temas abordados nos estudos.

Realizamos a pesquisa no mencionado repositório digital tendo em vista os descritores criança/infância e imprensa nas produções acadêmicas produzidas no período citado, nas seguintes áreas e subáreas de conhecimento: grande área do conhecimento: "Ciências Humanas"; área do conhecimento: "Educação"; e áreas de concentração: "Educação, Educação brasileira e História da Educação". A partir desse cruzamento de informações, obtivemos a cifra de 2.016 resultados (entre dissertações e teses). Sabíamos que a utilização dos descritores criança e infância aumentaria o número de resultados. Todavia, optamos por utilizar os dois descritores, pois entendemos não serem sinônimos no campo conceitual. Enquanto o primeiro designa um sujeito social, o segundo está associado a uma idade/período da vida. Optamos também por utilizar o descritor imprensa, tendo em vista que muitos pesquisadores poderiam ter escolhido a mencionada palavra-chave e não o descritor jornal. Da mesma forma que no cenário anterior, esta escolha mostrou-se problemática, na medida em que número significativo dos estudos que utilizam periódicos reportam-se a uma imprensa especializada de caráter educacional para os estudos de História da Educação. Foi necessária, então, a leitura dos resumos das dissertações e teses para definir com mais nitidez o escopo dos trabalhos.

Após a leitura dos resumos das 2.016 produções acadêmicas identificamos 29 estudos, distribuídos entre 15 dissertações e 14 teses, que utilizaram os jornais como fonte documental no processo de construção da narrativa. A seguir apresentamos a listagem dos estudos selecionados para essa análise ${ }^{6}$ :

Quadro 1 - Dissertações

Título/Autor(a)

"Em torno do berço": discursos sobre a educação da infância pobre parayhbana no Jornal A imprensa (1912-1922)

Solanja Silva Costa

Legislação e educação da infância na coleção de leis do império (1808-1889)

Kate Paula Nunes Dias

O filme Pixote, a lei do mais fraco e o governo das crianças marginalizadas (1980-1985)

\footnotetext{
${ }^{6}$ Para a referência bibliográfica completa das dissertações e teses selecionadas para a análise nesse artigo, ver: Plataforma Lattes (http://lattes.cnpq.br/).
} 


\begin{tabular}{|l}
\hline Luis Alberto Pereira Junior \\
\hline Os lugares da infância em processos de comunicação comunitária: Jornal O cidadão da Maré como experiência \\
Eunice Muruet Luna \\
\hline A infância nas páginas de jornal: discursos (re)produzidos pela imprensa paraense na primeira década do século XX \\
Welington da Costa Pinheiro \\
\hline Infância como crítica social: uma análise do suplemento "O Estadinho" (1984-1987) \\
Laís Elena Vieira \\
\hline "Pelo progresso do paiz": projetos para a educação de ingênuos na imprensa paulista em fins do século XIX \\
Kadine Teixeira Lucas \\
\hline A infância nos folhetins de A província de São Paulo/O Estado de São Paulo (1875-1889) \\
Aldení de Sousa \\
\hline Parques Infantis no Amazonas: 1940 a 1996 \\
Kelly Rocha de Matos Vasconcelos \\
\hline Histórias e sentidos da institucionalização da criança pobre em Cianorte \\
Fabiana Fernandes Ferreira Campiotto \\
\hline Ao abrigo da infâmia: as subvenções à proteção da criança na câmara municipal de São Paulo entre 1890 e 1927 \\
Ricardo Felipe Santos Costa \\
\hline Ler, verbo transitivo: o jornal A voz da infância na gestão Mário de Andrade \\
Merenice Merhej \\
\hline O jardim de infância da escola Americana, São Paulo: Continuidades e rupturas em sua trajetória Histórica (1870-1942) \\
Maira Ignacio da Silva \\
\hline Infância negada: um estudo sobre as relações sociais de meninas negras no asilo Santa Teresa (1855-1870) \\
Claudiane Santos Araújo \\
\hline A produça da crinça trans nas reporagens diglais: um olhar para os espaços educativos famila e escola \\
\hline
\end{tabular}

A produção da criança trans nas reportagens digitais: um olhar para os espaços educativos família e escola Ariane Pickersgill Arana

Fonte: Catálogo de Teses e Dissertações/CAPES.

\section{Quadro 2 - Teses}

\section{Título/Autor(a)}

Fios do novelo: crianças negras, educação e trabalho em Vassouras, 1871 a 1910

Alexandre Ribeiro Neto

A infância e sua escolarização nas páginas dos jornais cuiabanos (1910-1930)

Marijâne Silveira da Silva

Práticas e representações da institucionalização da infância: bebês e crianças bem pequenas na creche em Francisco Beltrão/PR (1980/1990)

Caroline Machado Cortelini Conceição

Aspectos da educação infantil no estado do Amazonas: o curso infantil Froebel no instituto Benjamin Constant e outros jardins de infância (1897-1933)

Pérsida da Silva Ribeiro Miki

A escolarização de crianças negras paulistas (1920-1940)

Marcia Luiza Pires de Araújo

"À terra, ao trabalho e à vida rural": políticas de assistência à infância desvalida em Minas Gerais e a escola Padre Sacramento,

São João Del-Rei, 1929-1972

Adélia Carolina Bassi

A infância e sua educação nas tramas de uma história do município de Taubaté (1870-1920)

Cesar Augusto Eugenio

Escola e infância: processo de institucionalização dos jardins-de-infância na capital do Maranhão no período de 1870 a 1930

Rachel Tavares de Morais 
História da Fundação Pestalozzi do Pará (1953-1975): os discursos político-social e educacional na assistência à criança excepcional

Cibele Braga Ferreira Nascimento

Infâncias por escrito. O Estadinho: um suplemento infantil catarinense (1972-1987)

Luciana Mara Espíndola Santos

História da Assistência à criança pobre em Rio Branco-Acre: Instituições, sujeitos e ações na década de 1940

Giane Lucélia Grotti

O instituto feminino de menores de Mogi Mirim: resistência, disciplina, submissão, violência e repressão (1937-1950)

Izalto Junior Conceição Matos

O Orfanato Santo Eduardo e a assistência às crianças pobres em Uberaba-MG (1920-1964)

Marilsa Aparecida Alberto Assis Souza

O instituto Orfanológico do Outeiro: assistência, proteção e educação de meninos órfãos e desvalidos em Belém do Pará (19031913)

Welington da Costa Pinheiro

Fonte: Catálogo de Teses e Dissertações/CAPES.

Entre 2013 e 2018, o número de dissertações e teses produzidas nos programas de pósgraduação em Educação que utilizaram jornais como fonte não apresentou um crescimento uniforme. Os anos que apresentam um maior volume na produção são os de 2014 , com $17 \%$ dos estudos, e de 2017 , com $24 \%$ das investigações. O referido conjunto de estudos foi produzido em programas de pósgraduação em Educação de todas as regiões brasileiras. Conforme Gráfico 1, podemos observar uma maior concentração de estudos produzidos em instituições acadêmicas da região Sudeste do país:

Gráfico 1 - Distribuição dos estudos dos Programas de pós-graduação em Educação que utilizaram jornais como fonte por regiões do Brasil (2013-2018)

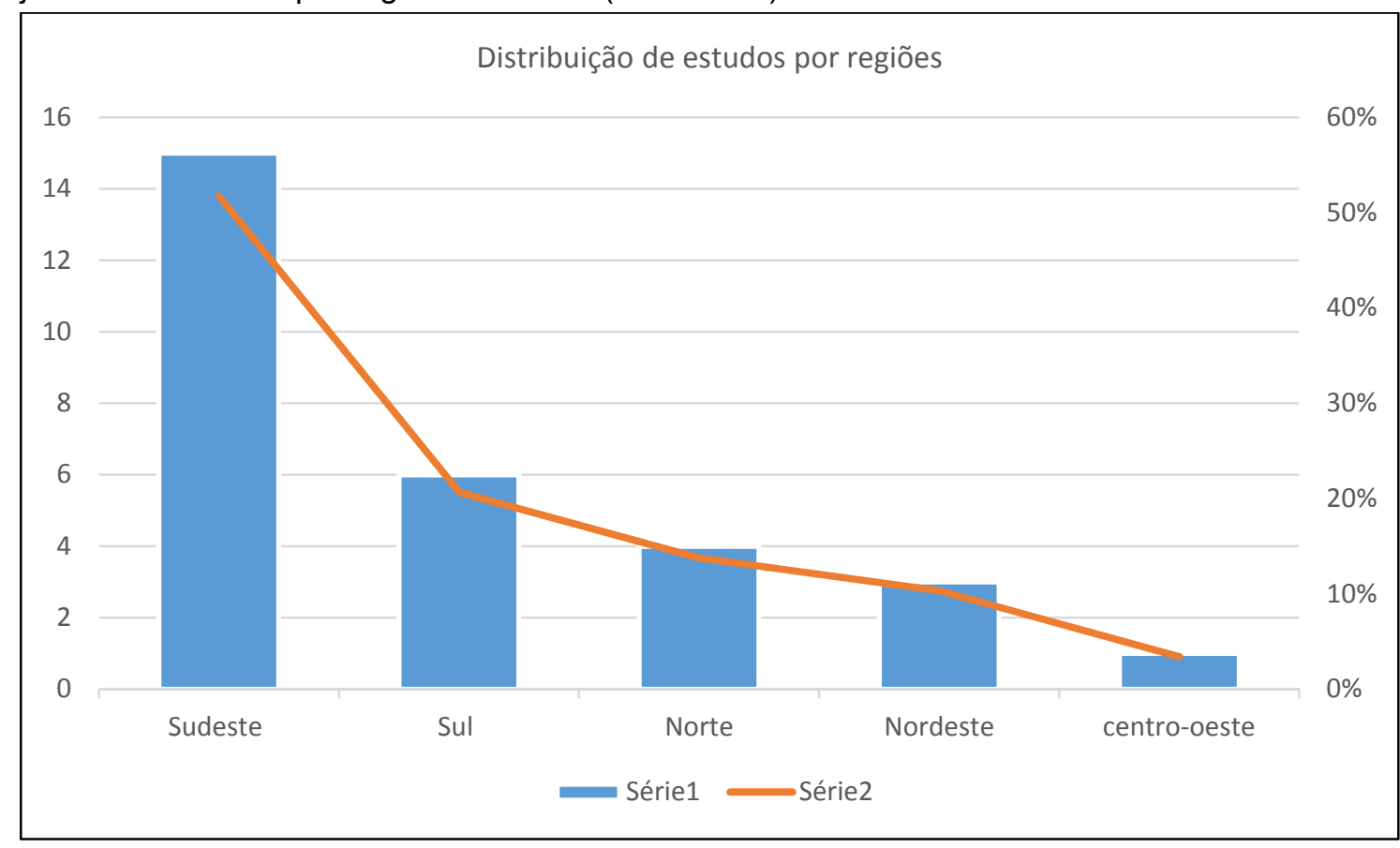

Fonte: Catálogo de Teses e Dissertações/CAPES. 
Além da região Sudeste possuir um maior número de programas de pós-graduação em Educação, instituições, tais como, a Pontifícia Universidade Católica de São Paulo (PUC-SP), a Universidade de São Paulo (USP), a Universidade Federal de Minas Gerais (UFMG) e a Universidade Estadual de Campinas (UNICAMP) têm produzido estudos na área da História da Educação há mais tempo, desde a década de 1970. O segundo maior conjunto de estudos foi encontrado na região Sul, que também possui instituições universitárias que produzem um significativo número de estudos acerca da História da Educação. Inclusive, dois dos principais periódicos científicos da área da História da Educação estão abrigados em portais de universidades sediadas na região Sul, a Revista Brasileira de História da Educação e a Revista História da Educação.

Os estudos selecionados são provenientes de vinte instituições universitárias distribuídas nas seguintes regiões:

Sudeste: Universidade São Francisco (USF) - 2 DI e 2 TE7; Universidade do Estado do Rio de Janeiro (UERJ) - 1 DI e 1 TE; Pontifícia Universidade Católica de São Paulo (PUC) - 1 DI; Universidade Federal de São Paulo (UNIFESP) - 1 DI; Universidade Estadual de Campinas (UNICAMP) - 1 DI e 1 TE; Universidade de São Paulo (USP) - 1 DI e 1 TE; Universidade Federal de Minas Gerais (UFMG) - 1 TE; Universidade Federal de Uberlândia (UFU) - 1 DI e 1 TE.

Sul: Universidade Federal de Santa Catarina (UFSC) - 1 DI; Universidade do Estado de Santa Catarina (UDESC) - 1 TE; Universidade Estadual de Maringá (UEM) - 1 DI; Universidade Federal do Rio Grande (FURG) - 1 DI; Universidade do Vale do Rio dos Sinos (UNISINOS) - 1 TE; Universidade Federal do Paraná (UFPR) - 1 TE.

Norte: Universidade Federal do Amazonas (UFAM) - 1 DI; Universidade Federal do Pará (UFPA) - 1 DI e 2 TE.

Nordeste: Universidade Federal da Paraíba (UFPB) - 1 DI; Universidade Federal do Maranhão (UFMA) - 1 DI; Universidade Federal do Rio Grande do Norte (UFRN) - 1 TE.

Centro-Oeste: Universidade Federal do Mato Grosso (UFMT) - 1 TE.

Dos 29 estudos selecionados para análise, 10 investigações - sendo 4 dissertações e 6 teses foram orientadas por docentes que atuavam em linhas de pesquisa dos programas de pós-graduação em Educação intituladas "História da Educação" e "História e Historiografia da Educação".

No Gráfico 2 abaixo apresentamos os dados sobre o recorte temporal dos estudos produzidos nos programas de pós-graduação em Educação que utilizaram o jornal como fonte entre 2013 e 2018.

Gráfico 2 - Recorte temporal dos estudos dos Programas de pós-graduação em Educação que utilizaram jornais como fonte (2013-2018)

7 TE: Tese. DI: Dissertação. 


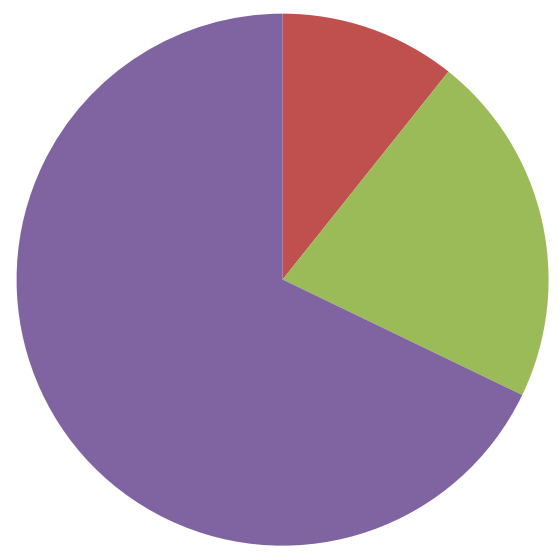

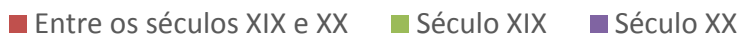

Fonte: Catálogo de Teses e Dissertações/CAPES.

Já no Gráfico 3 apresentamos os dados sobre as teses e dissertações que utilizaram o jornal como fonte, cujo recorte temporal foi o século XX.

Gráfico 3 - Recorte temporal dos estudos dos Programas de pós-graduação em Educação que utilizaram jornais como fonte (2013-2018), Século XX

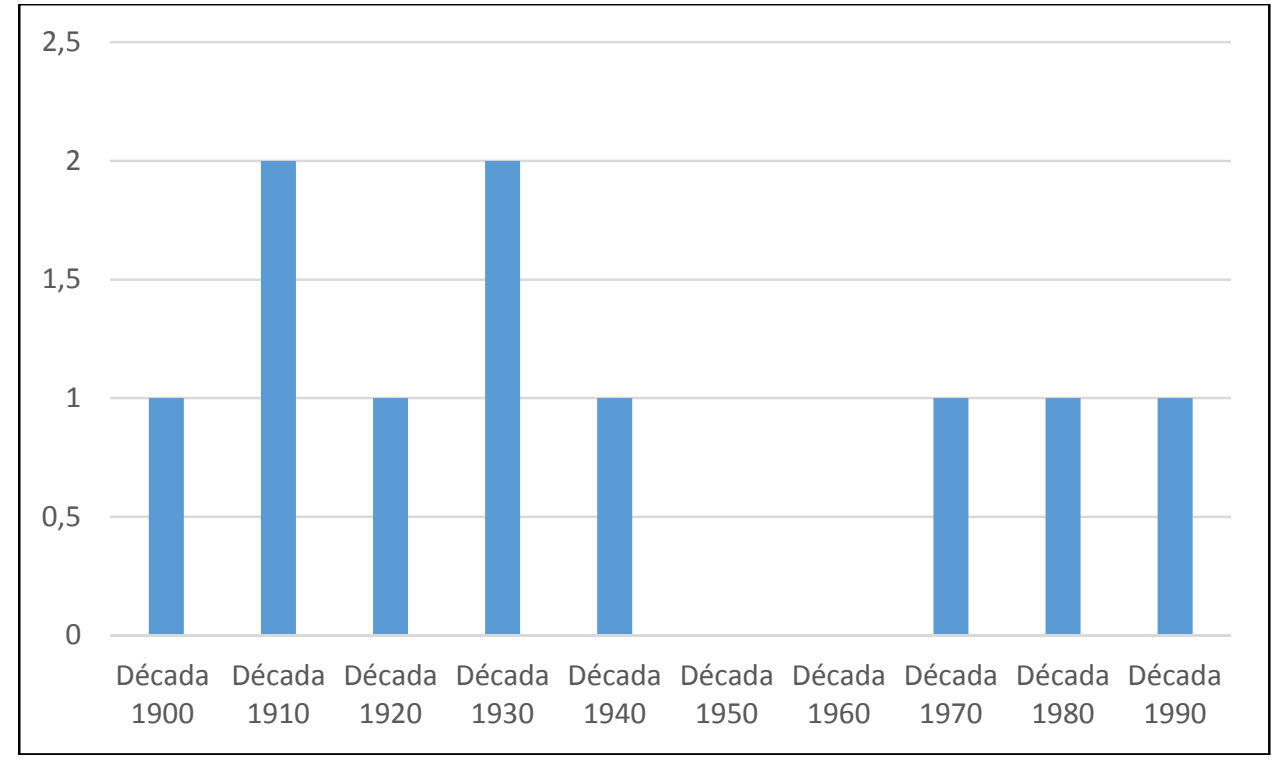

Fonte: Catálogo de Teses e Dissertações/CAPES.

Do total, $66 \%$ dos estudos que usaram o jornal como fonte possuem como recorte temporal o século XX. Possivelmente esta constatação relacione-se à expansão do mercado jornalístico brasileiro no último século e às profundas transformações então ocorridas no campo educacional brasileiro, seja do ponto de vista do discurso pedagógico ou da difusão da escolarização para a população do país. $\mathrm{Na}$ primeira metade do século XX tivemos a implementação do ideário da Escola Nova nas políticas educacionais do Brasil e o início do processo de escolarização em larga escala da população, 
sobretudo após a década de 1930. Observamos, conforme o Gráfico 3, que a maior parte das investigações se situa neste recorte temporal. Já na segunda metade do século XX ocorreu o fenômeno da democratização do ensino no Brasil, quando uma parcela significativa das crianças, adolescentes e jovens passou a frequentar os bancos escolares. Foi também no século XX que tivemos a instituição de uma legislação brasileira para a infância - o Código de Menores de 19278, o Código de Menores de $1979^{9}$ e o Estatuto da Criança e do Adolescente, em $1990^{10}$-, a qual engendrou um conjunto de políticas sociais para os considerados menores de idade que viviam em situação de vulnerabilidade social ou haviam cometido infração e para a população infantojuvenil trabalhadora. De certa forma esses processos históricos relativos à educação escolar e à assistência social foram abordados nos periódicos, mesmo que tangencialmente, permitindo assim a escrita da História. É importante observar ainda que há um conjunto de investigações cujo recorte temporal é o século XIX, conforme o Gráfico 2. Ou seja, as informações presentes nos jornais possibilitaram a construção de narrativas sobre outras infâncias, tais como os considerados juridicamente como ingênuos e a dos órfãos (muitos deles considerados juridicamente como expostos) que viveram no século XIX. Fato relevante, uma vez que as informações sobre esses grupos sociais não são de fácil acesso em outras fontes documentais.

\section{NARRATIVAS DE HISTÓRIA DA EDUCAÇÃO, JORNAIS E INFÂNCIAS PLURAIS}

Em apenas 11 estudos mencionados anteriormente, sendo 8 dissertações e 3 teses, somente os jornais publicados no Brasil foram utilizados como fonte documental nas investigações. ${ }^{11}$ Nas demais dissertações e teses, esta documentação fez parte de um conjunto com outras fontes, tais como, as legislações, os documentos escolares, as produções audiovisuais (com destaque para o cinema), os prontuários de instituições de abrigamento, as fotografias, os documentos de instituições privadas de atendimento, etc. Tendo em vista o critério da utilização de unicamente o jornal como a fonte documental no processo de construção da narrativa, selecionamos os seguintes estudos para análise daqui para frente nesse artigo, conforme Quadro 3:

Quadro 3 - Dissertações e teses dos Programas de pós-graduação em Educação que utilizaram somente o jornal como fonte documental (2013-2018)

\begin{tabular}{|c|l|c|c|c|c|}
\hline$N^{\circ}$ & \multicolumn{1}{|c|}{ Título } & Instituição & Autor(a) & $\begin{array}{c}\text { Tipo de } \\
\text { trabalho de } \\
\text { conclusão }\end{array}$ & $\begin{array}{c}\text { Data de } \\
\text { defesa }\end{array}$ \\
\hline 01 & $\begin{array}{l}\text { A infância nas páginas de jornal: discursos (re) } \\
\text { produzidos pela imprensa paraense na primeira } \\
\text { década do século XX }\end{array}$ & UFPA & Welington da \\
Costa Pinheiro & DI & 2013 \\
\hline 02 & Os lugares da infância em processos de & UERJ & Eunice Muruet & DI & 2014 \\
\hline
\end{tabular}

\footnotetext{
${ }^{8}$ BRASIL, Decreto-Lei número 17.943-A, de 12 de outubro de 1927.

${ }^{9}$ BRASIL, Lei número 6.667, de 10 de outubro de 1979.

${ }^{10}$ BRASIL, Lei número 8.069, de 13 de julho de 1990.

${ }^{11}$ Optamos por não utilizar as tipologias fonte documental primária ou secundária na nossa análise, uma vez que esta forma hierárquica de descrição da documentação está em desuso no campo da História.
} 


\begin{tabular}{|c|c|c|c|c|c|}
\hline & $\begin{array}{l}\text { comunicação comunitária: Jornal O cidadão da } \\
\text { Maré como experiência }\end{array}$ & & Luna & & \\
\hline 03 & $\begin{array}{l}\text { A infância e sua escolarização nas páginas dos } \\
\text { jornais cuiabanos (1910-1930) }\end{array}$ & UFMT & $\begin{array}{l}\text { Marijâne Silveira } \\
\text { da Silva }\end{array}$ & TE & 2015 \\
\hline 04 & $\begin{array}{l}\text { "Em torno do berço": discursos sobre a educação } \\
\text { da infância pobre parayhbana no Jornal A } \\
\text { Imprensa (1912-1922) }\end{array}$ & UFPB & $\begin{array}{l}\text { Solanja Silva } \\
\text { Costa }\end{array}$ & DI & 2015 \\
\hline 05 & $\begin{array}{l}\text { "Pelo progresso do paiz": projetos para a } \\
\text { educação de ingênuos na imprensa paulista em } \\
\text { fins do século XIX }\end{array}$ & PUC-SP & $\begin{array}{l}\text { Kadine Teixeira } \\
\text { Lucas }\end{array}$ & DI & 2016 \\
\hline 06 & $\begin{array}{l}\text { História da assistência à criança pobre em Rio } \\
\text { Branco-Acre: instituições, sujeitos e ações na } \\
\text { década de } 1940\end{array}$ & UFPR & $\begin{array}{l}\text { Giane Lucelia } \\
\text { Grotti }\end{array}$ & TE & 2016 \\
\hline 07 & $\begin{array}{l}\text { A infância no folhetim de A Província de São } \\
\text { Paulo/O Estado de São Paulo(1875-1889) }\end{array}$ & UNIFESP & Aldení de Sousa & DI & 2017 \\
\hline 08 & $\begin{array}{l}\text { Ler, verbo transitivo: o jornal A voz da infância na } \\
\text { gestão Mário de Andrade }\end{array}$ & USP & Merenice Merhej & DI & 2017 \\
\hline 09 & $\begin{array}{l}\text { Infâncias por escrito. "O Estadinho": um } \\
\text { suplemento infantil Catarinense (1972-1987) }\end{array}$ & UDESC & $\begin{array}{l}\text { Luciana Mara } \\
\text { Espíndola Santos }\end{array}$ & TE & 2017 \\
\hline 10 & $\begin{array}{l}\text { A produção da criança trans nas reportagens } \\
\text { digitais: um olhar para os espaços educativos } \\
\text { família e escolar }\end{array}$ & FURG & $\begin{array}{l}\text { Ariane Pickersgill } \\
\text { Arana }\end{array}$ & DI & 2018 \\
\hline 11 & $\begin{array}{l}\text { Infância como crítica social: uma análise do } \\
\text { suplemento "O Estadinho" (1984-1987) }\end{array}$ & UFSC & Laís Elena Vieira & DI & 2018 \\
\hline
\end{tabular}

Fonte: Catálogo de Teses e Dissertações/CAPES.

Identificamos que 10 dos estudos selecionados utilizaram como fonte documental jornais que circulavam no momento em que foram editados nos seguintes estados da federação: São Paulo (Folha de São Paulo, O Estado de São Paulo, Correio Paulistano, O Progresso, A Redempção), Santa Catarina (O Estado), Paraíba (A Imprensa), Acre (O Acre) e Pará (Folha do Norte, Província do Para). Uma dissertação utilizou como fonte documental um jornal comunitário ( $O$ cidadão da Maré) que possivelmente circulou preferencialmente na denominada "Zona Norte" da cidade do Rio de Janeiro. Já outra dissertação referendou o estudo com um jornal produzido para o público infantojuvenil que circulou somente na cidade de São Paulo ( $A$ voz da Infância). Há estudos que fizeram uso dos jornais (O Estado de São Paulo, Folha de São Paulo, Zero Hora) em formato digital postados na internet e, assim, com acesso mundial.

De maneira geral, as dissertações e teses analisaram um ou dois jornais no processo de construção da narrativa. Somente a tese intitulada "A infância e sua escolarização nas páginas dos jornais cuiabanos (1910-1930)", de autoria de Marijâne Silveira da Silva (2015), apresenta informações retiradas de 38 jornais que circularam no Estado do Mato Grosso entre 1910 e 1930. Há estudos que analisaram jornais que estão em circulação desde o século XIX até os dias atuais, como é o caso do jornal O Estado de São Paulo fundado em 1875. O periódico foi analisado no formato impresso na dissertação "A infância no folhetim de A Província de São Paulo/O Estado de São Paulo (1875-1889)", de autoria de Aldení de Sousa (2017), e, no formato digital, no estudo "A produção da criança trans nas 
reportagens digitais: um olhar para os espaços educativos família e escola", escrita por Ariane Pickersgill Arana (2018). O jornal $A$ voz da infância, que era produzido a partir de contribuições de crianças e editado pela Biblioteca Mário de Andrade $^{12}$, também circulou por três décadas. A longevidade de alguns periódicos evidencia então a relevância dessa fonte documental para os estudos da História da Educação, permitindo inclusive a realização de reflexões a partir de períodos cronológicos mais longos que possibilitam conhecer as permanências e rupturas nos discursos e na produção/circulação das representações sociais.

Diferentes gêneros jornalísticos, fotojornalismo e anúncios publicitários foram utilizados pelos pesquisadores no processo de análise das representações sociais e discursos acerca da infância brasileira presentes nos periódicos dos séculos XIX e XX, conforme o Quadro 413:

Quadro 4 - Gêneros jornalísticos/fotojornalismo/anúncios publicitários analisados nos estudos dos Programas de pós-graduação em Educação que utilizaram somente o jornal como fonte (2013-2018)

\begin{tabular}{|l|c|c|}
\hline \multicolumn{1}{|c|}{ Gêneros jornalísticos/Fotojornalismo/Anúncio publicitário } & TE & DI \\
\hline Anúncio publicitário & & 1 \\
\hline Artigo & 2 & 2 \\
\hline Coluna & & 1 \\
\hline Editorial & & 1 \\
\hline Folhetim & 1 & 1 \\
\hline Fotojornalismo & & 1 \\
\hline Reportagem & 1 & 1 \\
\hline Suplemento & & 1 \\
\hline
\end{tabular}

Fonte: Catálogo de Teses e Dissertações/CAPES.

A partir do Quadro 4 é possível perceber que os pesquisadores privilegiaram espaços específicos dos jornais para análise. Apenas a dissertação intitulada "A infância nas páginas de jornal: discursos (re) produzidos pela imprensa paraense na primeira década do século XX", de Welington da Costa Pinheiro (2013)14 fez usos de diferentes gêneros jornalísticos. Outro elemento importante a ser observado nos estudos selecionados é a predominância das análises dos textos em detrimento das imagens presentes nas matérias jornalísticas. Isto é relevante frente ao processo de modernização pelo qual passou a imprensa brasileira a partir sobretudo da década de 1950. As inovações tecnológicas, como a impressão offset e a modernização das técnicas relativas ao fotojornalismo, fizeram com que as imagens fotográficas ganhassem força pela rapidez com que davam a ver os acontecimentos (MAUAD, 2005). Entendemos que a opção pela análise dos textos pelos pesquisadores está associada também às escolhas metodológicas. Colocar o foco nas imagens fotográficas demanda o domínio de outras "ferramentas" metodológicas ainda pouco exploradas pelos pesquisadores da área da História Educação.

\footnotetext{
${ }^{12}$ A Biblioteca Mário de Andrade é a principal biblioteca pública da cidade de São Paulo tendo sido fundada em 1925.

${ }^{13}$ Gêneros jornalísticos diferentes foram utilizados em mais de um estudo.

${ }^{14}$ Disponível em: <http://repositorio.ufpa.br/jspui/handle/2011/4072>.
} 
A maior parte dos estudos sinalizou que a conservação das coleções dos jornais pesquisados era precária e, muitas vezes, as mesmas não apresentavam todos os números editados ao longo do tempo. Luciana Mara Espíndola Santos chama a atenção para o grave problema da conservação dos acervos das hemerotecas afirmando o seguinte:

Mesmo quando guardados nos arquivos supostamente a salvo da destruição, eles sofrem com a má conservação (geralmente em decorrência da falta de políticas públicas) e o esquecimento, só voltando a ter "sentido" quando pelas mãos do pesquisador é dado a falar. (SANTOS, 2017, p. 33).

Os estudos selecionados demonstraram que geralmente os interesses e as expectativas de grupos sociais que comandavam o país ou determinada região foram o "fio condutor" das representações sociais e/ou discursos expressos nos textos jornalísticos sobre os contextos infantis. Vale lembrar que, de maneira geral, os jornais brasileiros até a metade do século XX eram "alinhados" a determinados grupos políticos ou econômicos (especialmente partidos políticos), produzindo um discurso jornalístico que se ancorava em tais interesses. Posteriormente, a imprensa passou a ter nos anúncios publicitários uma fonte indispensável de recursos, o que possibilitou o início da profissionalização, com vistas a um jornalismo de caráter investigativo. Durante o período do Estado Novo (1937-1945) e da ditadura militar (1964-1985), os periódicos foram censurados de diferentes formas. Os estudos de Laís Elena Vieira (2018), Luciana Mara Espíndola Santos (2017) e Merenice Merhej (2017) demonstraram que mesmo os periódicos que eram produzidos a partir da produção artística e textual das crianças e adolescentes, tais como, os suplementos infantis e o jornal da Biblioteca Mário de Andrade, foram editados a partir de problemas e expetativas oriundas do "mundo adulto".

Uma parcela significativa dos/as leitores dos jornais brasileiros que subsidiaram a construção das narrativas aqui coletadas constituía-se de uma elite composta sobretudo por intelectuais, políticos e educadores até a metade do século XX. Posteriormente, o público leitor dos mencionados periódicos diversificou-se, especialmente após a emergência da "era digital". Esse fato informa sobre a amplitude do processo de circulação de informações relativas à educação brasileira na imprensa.

$\mathrm{Na}$ análise das dissertações e teses que fizeram uso do jornal como fonte documental, identificamos que, dos 11 estudos, 7 pautaram-se na perspectiva historiográfica da História Cultural na construção das narrativas. Conforme afirma Souza (2018), essa é a perspectiva historiográfica que tem norteado uma grande quantidade de estudos da História da Educação nas últimas duas décadas. Em relação à área da História da Educação, foram citados nas dissertações e teses de forma bastante frequente os seguintes autores: Antônio Nóvoa, Maria Helena Câmara Bastos, Maria Stephanou e José Gonçalves Gondra. Já em relação à História da Infância, os pesquisadores utilizaram como referência predominante as reflexões de autores como: Philippe Ariès, Moisés Kulhmann Junior, Mary del Priore, Maria Luiza Marcílio e Ilma Rizzini. A maior parte dos autores citados são pesquisadores brasileiros, demostrando então a existência de uma historiografia já mais "amadurecida" nas referidas áreas. A necessidade de problematizar as conexões existentes entre as produções da História da Infância e da 
História da Educação efetuadas no Brasil nas últimas décadas também esteve presente com certa constância nos estudos selecionados.

Os aportes teórico-metodológicos utilizados para a análise das matérias jornalísticas presentes nos periódicos das dissertações e teses foram diferentes. Dos 11 trabalhos selecionados, 3 dissertações utilizaram as contribuições do filósofo russo Mikhail Bakhtin na análise dos textos presentes nos jornais (PINHEIRO, 2013; LUNA, 2014; MERHEJ, 2017). Nesse caso, os textos dos jornais foram analisados sob a perspectiva da hermenêutica, sendo compreendidos como produto de um conjunto de fenômenos políticos e socioculturais. Duas dissertações utilizaram em termos teóricometodológicos os aportes pensados pelo filósofo francês Michel Foucault, entendendo os textos dos jornais com um discurso atravessado por relações de poder (ARANA, 2018; COSTA, 2015). Identificamos 4 estudos, sendo 3 teses e 1 dissertação, que utilizaram o conceito de representação social enunciado nos trabalhos do historiador francês Roger Chartier, no que tange aos referenciais teórico-metodológicos (GROTTI, 2016; SANTOS, 2017; SILVA, 2015; SOUSA, 2017). Nesses estudos os textos de caráter jornalístico são entendidos como algo que produz/circula representações sociais que contribuem sobremaneira no processo de emergência/permanência dos "cenários" sociais.

Além destas perspectivas teórico-metodológicas, 2 dissertações percorreram outros "caminhos". A dissertação intitulada "Pelo progresso do paiz": projetos para a educação de ingênuos na imprensa paulista em fins do século XIX" (LUCAS, 2016), foi redigida a partir das contribuições da historiadora Tania de Luca, especialista da área da História no Brasil na pesquisa de impressos, e das pesquisadoras Heloisa Cruz e Maria do Rosário Peixotto. O estudo "Infância como crítica social: uma análise do suplemento "O Estadinho" (1984 - 1987)" (VIEIRA, 2016), por sua vez, utilizou os aportes pensados pelo do pensador alemão Walter Benjamim relativos à noção de "experiência" (Erfahrung) no processo de análise das fontes.

Cinco temas pautaram as investigações das 11 dissertações e teses. No Quadro 5 abaixo apresentamos os temas, bem como o número de estudos em que estes estiveram presentes.

Quadro 5 - Temas das dissertações e teses dos estudos dos Programas de pós-graduação em Educação que utilizaram somente o jornal como fonte (2013-2018)

\begin{tabular}{|l|c|c|}
\hline \multicolumn{1}{|c|}{ Temas } & DI & TE \\
\hline Criança trans & 1 & \\
\hline Infância em geral & 3 & \\
\hline Infância pobre & 1 & 1 \\
\hline Processo de escolarização & 1 & 1 \\
\hline Produção artística/textual infantile & 2 & 1 \\
\hline
\end{tabular}

Fonte: Catálogo de Teses e Dissertações/CAPES.

Tendo em vista esses cinco temas investigados nas dissertações e teses, é possível conhecer parte das representações sociais e discursos acerca das crianças brasileiras que viveram em diferentes contextos históricos e sociais enunciadas em periódicos brasileiros. Uma parcela significativa dos estudos forneceu indicativos no sentido de que os jornais foram um dos principais veículos, 
sobretudo no século $X X$, de difusão do ideário que entende que a escola é o espaço preferencial das crianças das diferentes classes sociais.

Em relação ao tema "infância em geral", os jornais apresentaram duas representações sociais de criança. Por um lado, a criança ingênua presente nas diferentes seções dos periódicos e, por outro, a criança pobre "relegada à própria sorte", noticiada frequentemente em determinadas seções (polícia, reportagens sobre os problemas sociais, etc.). Em relação ao tema da "infância pobre", os jornais utilizados nas dissertações e teses descreveram as vivências das crianças em cenários sociais diversos, tais como, nos seringais da Amazônia, como filhos e filhas de imigrantes ou ainda andando pelas ruas das cidades a mendigar. Em relação a esse tema, os jornais foram também porta-vozes da necessidade de institucionalizar a infância considerada pobre, ou então, impor a esta população uma "nova identidade" que atendesse aos ideais de civilidade e disciplina almejados pelos políticos e pelos educadores. Por sua vez, os estudos que tinham como tema os "processos de escolarização" enunciaram a necessidade de produzir uma infância letrada tendo como locus a escola, conforme os interesses do Estado brasileiro. Ainda em relação ao mencionado tema, as crianças pobres eram apresentadas nos textos jornalísticos sob a perspectiva da vitimização em discursos que as associavam aos problemas sociais, assim como a exclusão escolar especialmente nos jornais editados após a década de 1970.

Além das referidas representações sociais e discursos, os jornais tematizaram também a criança urbana e escolarizada, ou seja, aquela oriunda das camadas médias da sociedade brasileira no século XX. Essas crianças foram convidadas a produzir conteúdo publicado em seções infantis. Todavia, como afirmamos anteriormente, as pesquisas sinalizaram que neste suposto protagonismo as crianças foram raras vezes um "sujeito de fala". A dissertação "A produção da criança trans nas reportagens digitais: um olhar para os espaços educativos família e escola", mostrou, por sua vez, como as "vozes" autorizadas dos especialistas foram convocadas para validar os argumentos de determinados discursos. Essa é inclusive uma das principais características do discurso jornalístico nos dias atuais quando este aborda a temática da infância (PONTE, 2005).

\section{PALAVRAS FINAIS}

Nas últimas décadas, os historiadores da educação têm utilizado uma multiplicidade de fontes em suas pesquisas. Os jornais, como demonstramos nesse artigo, emergem como uma fonte que possibilita a ampliação dos temas de estudo do campo da História da Educação. Dentre esses temas, conforme inferimos nesse texto, destaca-se o relativo às diversas infâncias presentes no país ao longo do tempo. Como vimos, os jornais permitiram conhecer as representações sociais e os discursos sobre crianças que viveram em diferentes contextos sociais e históricos. Compreendemos, por fim, que a produção de estudos, sejam eles dissertações ou teses, produzidos a partir de conexões entre a História da Infância e da Educação são extremamente necessários para o país. O conhecimento da História dessa infância plural pode contribuir sobremaneira para que as políticas educacionais implementadas na atualidade tenham maior êxito, bem como na formulação de novas propostas. 


\section{REFERÊNCIAS}

1. ARANA, Ariane Pickersgill. A produção da criança trans nas reportagens digitais: um olhar para os espaços educativos família e escola. 2018. 196 f. Dissertação (Mestrado em Educação) Universidade Federal do Rio Grande, Rio Grande, 2018.

2. BARDIN, Laurence. Análise de Conteúdo. Lisboa: Edições 70, 1977.

3. BASTOS, Maria Helena Câmara; CATANI, Denice Bárbara (Org.). Educação em Revista: a imprensa periódica e a história da educação. São Paulo: Escrituras, 2002.

4. BRITES, Olga. Infância, higiene e saúde na propaganda (usos e abusos nos anos 30 a 50). Revista Brasileira de História, São Paulo, v. 20, p. 249-278, 2000. http://dx.doi.org/10.1590/S010201882000000100011

5. COSTA, Solanja Silva. "Em torno do berço": discursos sobre a educação da infância pobre parayhbana no Jornal A Imprensa (1912-1922). 2015. 153 f. Dissertação (Mestrado em Educação) Universidade Federal da Paraíba, João Pessoa, 2015.

6. DAMINELLI, Camila Serafim. Em caso de crime, por que não antecipar? Debates sobre menoridade na imprensa durante a vigência do Código de Menores (Santa Catarina, 1979-1990). História Revista (ONLINE), v. 23, p. 128-147, 2018. https://doi.org/10.5216/hr.v23i1.37774

7. DIONÍSIO, Ana Carolina; GIRARDELLO, Gilka Elvira Ponzi. Corpo, Infância e Publicidade (décadas de 1940 e 1950). In: SCHREINER, Davi Félix; PEREIRA, Ivonete; AREND, Silvia Maria Fávero (Org.). Infâncias brasileiras: experiências e discursos. Cascavel: Ed. UNIOESTE, 2009. p. 191-211.

8. FARIA FILHO, Luciano M. de. O jornal e outras fontes para a história da educação mineira do século XIX: uma introdução. In: ARAÚJO, José Carlos Souza; GATTI JÚNIOR, Décio (Org.). Novos temas em História da Educação brasileira: instituições escolares e educação na imprensa. Uberlândia: Autores Associados/EDUFU, 2002. p. 133-151.

9. FINKELTEIN, Barbara. La incorporacion de la infancia a la historia de la educación. Revista de Educación, Madrid, n. 281, p. 19-46, 1986.

10. GROTTI, Giane Lucélia. História da assistência à criança pobre em Rio Branco-Acre: Instituições, sujeitos e ações na década de 1940. 2016. 214 f. Tese (Doutorado em Educação) - Universidade Federal do Paraná, Curitiba, 2016. 
KUHLMANN JR., Moisés; LEONARDI, Paula. História da Educação no quadro das relações sociais. Revista História da Educação (online), Porto Alegre, n. 51, v. 21, p. 207-227, 2017. http://dx.doi.org/10.1590/2236-3459/66163.

LUCAS, Kadine Teixeira. "Pelo progresso do paiz": projetos para a educação de ingênuos na imprensa paulista em fins do século XIX. 2016. 208 f. Dissertação (Mestrado em Educação) Pontifícia Universidade Católica de São Paulo, São Paulo, 2016.

LUNA, Eunice Muruet. Os lugares da infância em processos de comunicação comunitária: Jornal O Cidadão da Maré como experiência. 2014. 197 f. Dissertação (Mestrado em Educação) Universidade Estadual do Rio de Janeiro, Rio de Janeiro, 2014.

MAGALDI, Ana Maria B. M.; XAVIER, Libânia Nacif (Org.). Impressos e História da Educação: usos e destinos. Rio de Janeiro: 7 Letras, 2008.

MAUAD, Ana Maria. Flávio Damm, profissão fotógrafo de imprensa: a fotojornalismo e a escrita da história contemporânea. História, São Paulo, v. 4, n. 2, p. 41-78, 2005. http://dx.doi.org/10.1590/S0101-90742005000200003

16. MERHEJ, Merenice. Ler, verbo transitivo: o jornal A voz da infância na gestão Mário de Andrade. 2017. 120 f. Dissertação (Mestrado em Educação) - Universidade de São Paulo, São Paulo, 2017.

17. MOURA, Esmeralda Blanco B. de; AREND, Silvia Maria Fávero. Um norte em comum: infância no sul do Brasil na produção historiográfica brasileira. In: CARDOSO, José Carlos et al. (Org.). História das Crianças no Brasil Meridional. São Leopoldo: Oikos; Editora Unisinos, 2016. p. 37-56.

PINHEIRO, Welington da Costa. A infância nas páginas de jornal: discursos (re)produzidos pela imprensa paraense na primeira década do século XX. 2013. 150 f. Dissertação (Mestrado em Educação) - Universidade Federal do Pará, Belém, 2013.

PONTE, Cristina. Crianças em notícia: a construção da infância pelo discurso jornalístico (19702000). Lisboa: Imprensa de Ciências Sociais, 2005.

SANTOS, Luciana Mara Espíndola. Infâncias por escrito. "O Estadinho": um suplemento infantil catarinense (1972-1987). 2017. 360 f. Tese (Doutorado em Educação) - Universidade do Estado de Santa Catarina, Florianópolis, 2017.

SILVA, Marijâne Silveira da. A infância e sua escolarização nas páginas dos jornais cuiabanos (19101930). 2015. 188 f. Tese (Doutorado em Educação) - Universidade Federal do Mato Grosso, Cuiabá, 2015. 

(1875-1889). 2017. 192 f. Dissertação (Mestrado em Educação) - Universidade Federal de São Paulo, Guarulhos, 2017.

SOUZA, Sauloéber Tarsio de. A historiografia da educação brasileira a partir da leitura de periódicos científicos especializados: RBHE e HISTEDBR on line (2000-2010). Revista de História e Historiografia da Educação, Curitiba, v. 2, n. 5, p. 179-210, 2018. http://dx.doi.org/10.5380/rhhe.v2i5.57654 1987). 2018. 210 f. Dissertação (Mestrado em Educação) - Universidade Federal de Santa Catarina, Florianópolis, 2018.

\section{Silvia Maria Fávero Arend}

Professora do Departamento de História. Professora do Programa de Pós-graduação em História. Professora do Programa de Pós-graduação em Educação.

\section{Aline Fátima Lazarotto}

Professora do Curso de graduação em Pedagogia. Doutoranda do Programa de pós-graduação em Educação da Universidade do Estado de Santa Catarina.

Como citar este documento:

AREND, Silvia Maria Fávero; LAZAROTTO, Aline Fátima. História da Educação e Jornais: em busca de uma infância plural. Reflexão e Ação, Santa Cruz do Sul, v. 28, n. 3, p. 214-230, ago. 2020. ISSN 19829949. Disponível em: < https://online.unisc.br/seer/index.php/reflex/article/view/13678 >. Acesso em: doi:https://doi.org/10.17058/rea.v28i3.13678. 